\title{
State of Legislative and Normative Art in the Fields of the Environment, Health and Security of European Electrical and Electronic Equipment
}

\author{
Hassanzadeh Merdad $^{1 *}$, Metz Renaud ${ }^{2}$ \\ ${ }^{1}$ Schneider Electric, Energy Management - Power System, Site Technopole 3A17, 28 Rue Henri Tarze, 38050 Grenoble \\ Cedex 9, France \\ ${ }^{2}$ L2C - CNRS 5221, Université Montpellier (Université Claude Bernard, Lyon1), Bâtiment 11 - 3ème étage, Case courrier 26 \\ Place Eugène Bataillon, 34095 Montpellier Cedex 5, France
}

Corresponding Author Email: renaud.metz@umontpellier.fr

https://doi.org/10.18280/ejee.224-501

Received: 17 April 2020

Accepted: 10 September 2020

\section{Keywords:}

standards, WEEE, RoHS, REACh, ErP, CEI

62430, ISO 14044, environmental legislations

\begin{abstract}
Electricity is becoming increasingly important in our modern life, particularly in developed countries and recent generations. This contemporary energy allows smart programming and more refined uses. As a result, there is a need for better energy efficiency of Electrical and Electronic Equipment (EEE). In this context, the design of EEE must meet statutory obligations in order to reduce their consumption of primary energy by considering equipment over their whole life cycle. European legislation (WEEE, RoHS, ErP, REACh) has played a major role in deep technological change and has placed the environment at the center of the sector's interests. This article presents some of the many recent developments in normative and legislative matters.
\end{abstract}

\section{INTRODUCTION}

In the paradigm of a systemic and/or holistic approach of energy through life cycle framework, the global chain of energy transformation should henceforth be considered as:

$$
\mathrm{E}_{\text {primary }} \rightarrow \mathrm{E}_{\text {final }} \rightarrow \mathrm{E}_{\text {useful }}
$$

Useful energy refers to the energy actually used to accomplish a given task and is directly dependent on the performance of the final equipment. The final energy is actually the energy charged to the consumer. Eventually, primary energy stands for an energy form found in nature such as falling and flowing water, wind, fossil and mineral fuels... There are two kinds of qualities of energy: heat (low-quality) and electricity (high-quality) generation. Electricity is subjected to a human engineered conversion process that can be later advantageously and efficiently converted to any forms of energy such as: heat but also mechanical, light, heat, etc...

Viewed globally, the conversion of the chemical energy embodied in coal or natural gas is available as heat at high temperature with a loss of about $30 \%$ in actual exploitation conditions [1-3]:

$$
\mathrm{E}_{\text {primary }} \rightarrow \sim-31 \% \rightarrow \mathrm{E}_{\text {final }}
$$

Electricity such as oil are energy carriers. Crude oil needs to be extracted, carried, refined and distributed. The true conversion of chemical primary energy to fuel oil is about 1.1. In a very different way, the thermal conversion of coal, natural gas or shale to electricity reaches painfully $30 \%$ in worldwide true exploitation conditions. The losses due to electricity generation at the world level taking into account the difficulty of managing its storage [1-4] are significant:

$$
\mathrm{E}_{\text {primary }} \rightarrow \sim-63 \% \rightarrow \mathrm{E}_{\text {carrier }} \rightarrow \sim-17 \% \rightarrow \mathrm{E}_{\text {final,electricity }}
$$

(The share of electricity production in the worldwide greenhouse gas emissions is by far the largest with about $40 \%$ [5]).

Losses are even larger in the nuclear industry. In fact, despite a close-to-zero emission during the use phase [5], turbines used in nuclear power plants convert thermal energy to electricity with an energy efficiency of about $30 \%$. It follows that $1 \mathrm{kWh}$ billed to a customer requires an input of about $3 \mathrm{kWh}$ from the heat generated by the nuclear fission of uranium fuel:

$$
1 \mathrm{kWh}_{\text {electrical }} \sim 3 \mathrm{kWh} \text { primary,nuclear }
$$

Notwithstanding this assessment, there is a potential of improvement of the energy efficiency of electrical equipment. For instance, electric motors convert electrical energy into mechanical motion with fair efficiency. The typical efficiency of an electric car is about $\frac{E_{\text {useful }}}{E_{\text {final }}} \sim 50 \%$ in real conditions. This creates value creation potential depending on the primary energy implemented in the whole process. Indeed, the true efficiency may decrease from about: $\frac{E_{\text {useful }}}{E_{\text {primary,wind,solar }}} \sim 45 \%$ (in an ideal case), $\frac{E_{\text {useful }}}{E_{\text {primary, } \mathrm{C}, \mathrm{CH} 4}} \sim 20 \%$ up to $\frac{\mathrm{E}_{\text {useful }}}{\mathrm{E}_{\text {primary,nuclear }}} \sim$ $17 \%$, considering the origin of electricity: from wind and photovoltaic power plants, $\mathrm{C}$ and $\mathrm{CH}_{4}$ : cold and natural gas power plant and nuclear power plant respectively. In that respect, electricity continues to assert itself as the transportation fuel of the future, with global electricity demand growing by 4\% in 2018 to more than 23000 TWh [6]. This rapid growth is pushing electricity towards a $20 \%$ share in total final consumption of energy [6]. In this context of growth in 
energy consumption and few other bad forecasting [7], several laws and standards have emerged. The purpose of this article is to show how these texts articulate to structure and improve the life cycle of EEE and the different strategies implemented in the collection and recycling of this category of waste.

\section{EUROPEAN REGLEMENTATION}

European regulation over the whole product life cycle has strengthened since the early 2000s. The pioneer directives (RoHS, WEEE, EuP) and regulation (REACh) have been declined and/or revised in myriad European legislation texts which request a permanent regulatory watch. Moreover, proactive industrial strategies have been displayed by large companies or trade unions. One example may be: "We believe the best gas is no gas" [8].

\subsection{RoHS Directive}

RoHS Directive 2002/95/EC-acronym for Restriction of the use of Hazardous Substances in EEE was adopted in 2003 by the European Union [9]. It aims to restrict the use of toxic substances considered dangerous for the environment and especially for health. It was transposed into French law on the first January of 2006. The RoHS Directive currently limits its scope to devices whose operating voltage does not exceed $1 \mathrm{kV}$ $\mathrm{AC}$ and $1.5 \mathrm{kV}$ DC current. Typical applications are household appliances, computer and telecommunications equipment, electrical and electronic tools, lighting equipment, toys, automatic dispensers, leisure and sports equipment. Primary and secondary batteries are not covered by the RoHS directive: they benefit from a specific treatment according to 2006/66 / EC directive [9]!

RoHS restricts the use of four metals in the manufacture of electronic and electrical equipment: lead $(\mathrm{Pb})$, mercury $(\mathrm{Hg})$, cadmium $(\mathrm{Cd})$, hexavalent chromium VI $\left(\mathrm{Cr}^{\mathrm{VI}}\right)$ and two flame retardants: Po-lybromodiphenyls (PBBs) and polybrominated diphenyl ethers (PBDEs), used in various polymers and phthalates (DEHP, BBP, DBP and DOBP), the former being used to soften the polymers especially in the cable industry. The difficulty of implementing this directive led to the definition of maximum concentrations limitations (Table 1). It shall be the duty of the manufacturers but also the importers and distributors to ensure that these new restrictions do not alter product design and, if possible find substitutes. RoHS does not require any specific labelling even if many manufacturers have created their own compliance mark. The only legal indication of RoHS compliance is the CE marking: CE.

Table 1. Permissible mass ratio of hazardous substances in a homogeneous material (RoHS 3: 22 July 2019) [9]

\begin{tabular}{cc}
\hline Hazadous substances & $\begin{array}{c}\text { Maximum authorized mass } \\
\text { concentration }\end{array}$ \\
\hline Lead $(\mathrm{Pb})$ & $0.1 \%$ \\
Mercury $(\mathrm{Hg})$ & $0.1 \%$ \\
Hexavalent Chromium $\left(\mathrm{Cr}^{\mathrm{VI}}\right)$ & $0.1 \%$ \\
Cadmium $(\mathrm{Cd})$ & $0.01 \%$ \\
Polybromobiphenyles (PBB) & $0.1 \%$ \\
Bis (2- ethylexyyl) phthalate & $0.1 \%$ \\
(DEHP) & $0.1 \%$ \\
Butylbenzyl phthalate (BBP) & $0.1 \%$ \\
Dibutyl phthalate (DBP) & $0.1 \%$ \\
Diisobutyl phthalate (DOBP)
\end{tabular}

For the 10 substances, the maximum concentration has to be considerate by homogeneous material. A homogeneous material is either a material with a uniform composition throughout or a material that consists of a combination of materials, that cannot be disjointed or separated into different materials by mechanical actions such as unscrewing, cutting, crushing, grinding or abrasive processes. (By instance, a surface treatment layer of several nanometers on the top of a metallic part is a homogeneous material). It should be noted that RoHS Directive has inspired China, Korea, Japan, Turkey, Ukraine and the US states of California and New Jersey with sometimes harsher requirements such as China.

These limitations facilitate end-of-life treatment of equipment and reinforce the WEEE Directive.

\subsection{WEEE Directive}

WEEE Directive 2002/96 (Waste Electrical and Electronic Equipment Directive [9]) is closely related to the RoHS Directive. It is applicable to all member states of the European Union. Its objective is to contribute to sustainable production and consumption, as a matter of priority, through the prevention of WEEE and, in addition, through reuse, recycling and other forms of recovery of this waste. The idea is to reduce waste and contribute to the efficient use of resources and the recovery of valuable secondary raw materials. It also aims to improve the environmental performance of all operators involved in the life cycle of EEE, e.g. producers, distributors and consumers, and in particular operators involved in the collection and treatment of WEEE.

WEEE introduces the principle of extended producer responsibility for the management of electrical and electronic waste of household and industrial appliances. The objective is to internalize the external costs of a product to the end of its life, and to reduce the generation of waste.

In December 2008, the European Commission proposed to revise the directive in order to cope with the increasing flow of waste. The new WEEE Directive 2012/19 / EU was adopted on July $4^{\text {th }}, 2012$, entered into force on February $14^{\text {th }}, 2014$ [9]. As a result, WEEE Directive 2002/96 / EC was repealed with effect from February $14^{\text {th }}, 2014$ [9].

The WEEE Directive has been implemented on the basis of specific decisions taken by each Member State of the European Union, given that national transposition cannot be less demanding than the Directive itself.

For products falling within the scope of the Directive, the requirements imply obligations for value chain actors, in particular producers of EEE, i.e. a report ensuring that the product complies with the regulations. The latter is sent to an accredited body which authorizes the $C €$ marking.

Producers must also affix to each household electrical and electronic equipment placed on the market after August $13^{\text {th }}$, 2005 the pictogram: If size permits, this pictogram appears on the packaging and on the warranty documents and the instructions for use that accompany it.

In short, this directive empowers producers (importers, introducers, distributors and even remote sellers from abroad) to take in:

- management of end-of-life products: collection and recovery, actually often achieved by paying a financial contribution to not-for-profit WEEE producer responsibility organizations [10].

- considering the end of life from the design phase by 
facilitating recycling. The design of a device should not stop anymore at the assembly phase but must now integrate the future disassembly.

Distributors are also subject to obligations such as:

- taking back a used product against the purchase of a similar product. This is the so-called one-for-one obligation.

- the marking of the contribution to eco-participation on the customer's purchase invoice.

- lastly and more recently, the non-mandatory take-back of used small electrical and electronic equipment through selfservice collection containers [10]

\subsection{ErP Directive}

ErP Directive (Energy-related Products Directive, formerly Eco-design for Energy using Products (2005/32 / EC)) is the 2009/125 / EC European Directive [9]. It establishes a framework for setting eco-design requirements for products that impact on energy consumption during their use phase. It is a framework directive that defines the legal context within which implementing measures are developed. These measures establish eco-design requirements for energy-using (computers, washing machines, ...) and energy-related products (water saving taps, showerheads, ...). This directive recommends taking action during the design phase to reduce environmental impacts over the entire life cycle. In fact, most of the costs and environmental impacts are often determined at this stage.

The purpose of the ErP Directive was to enable the European Union to meet its obligations under the Kyoto Protocol (1998) of the United Nations. Under this protocol and through the Energy Efficiency Directive (2012/27/EU), the European union has committed a plan in reference of the year 1990 (Table 2).

Table 2. European union commitment by the year 2020 and 2030 (revised upwards in 2018)

\begin{tabular}{ccc}
\hline Commitment & $\mathbf{2 0 2 0}$ & $\mathbf{2 0 3 0}$ \\
\hline $\begin{array}{c}\text { Reduce greenhouse gas } \\
\text { emissions }\end{array}$ & $-20 \%$ & $-40 \%$ \\
$\begin{array}{c}\text { Increase energy efficiency } \\
\text { (or reduce energy }\end{array}$ & $+20 \%$ & $+32.5 \%$ \\
$\begin{array}{c}\text { consumption) by } \\
\text { Increase the share of }\end{array}$ & $(-20 \%)$ & $(-32.5 \%)$ \\
$\begin{array}{c}\text { renewable energy sources in } \\
\text { energy consumption }\end{array}$ & $+20 \%$ & $+32 \%$ \\
\end{tabular}

Early July 2019, there was horizontal measure covering standby/off mode and 25 product groups to be considered in priority for implementing measures. From these groups, there are those for which no label is foreseen: electric motors, power transformers, servers and data storage products, ... and 15 for which a label is compulsory: air conditioners, domestic ovens, lamps, household dishwashers, ...Indeed, ErP directive is associated with the framework regulation: Energy Labelling Regulation (EU) 2017/1369 [9]. Since the first of January 2019, suppliers (manufacturers, importers or authorized representatives) need to register their appliances, which require an energy label in the European Product Database for Energy Labelling (EPREL) [11]. This label allows consumers to buy the most energy efficient products and other criteria to perform a better informed purchase choice: information about water used per washing cycle, storing capacity, noise emitted, ... New labels will be visible as of March $1^{\text {st }}, 2021$, with $\mathrm{A}$ to $\mathrm{G}$ energy labels (excluding confusing $\mathrm{A}+++, \mathrm{A}++$ and $\mathrm{A}+$ ) and a QR (Quick Response) code with which consumers will be able to get additional data inserted by manufacturers into EPREL.

In order to facilitate comparison between different technologies, the Energy Efficiency Directive expresses how much primary energy is used to generate a unit of electricity or a unit of useable thermal energy, with a conversion factor (primary energy factor), which is unique for all the countries of the European Union (previously 2.5):

$$
2.1 \mathrm{kWh}_{\text {primary }} \rightarrow 1 \mathrm{kWh} \text { final }
$$

This conversion factor implies that 1 unit of electricity requires an input of 2.1 units of primary energy. This assumes all power generation in the EU to have about $48 \%$ efficiency $\left(\frac{100}{2.1} \sim 48 \%\right)$ even fluctuating renewable energy flows such as sunlight, wind, tides, plant growth and geothermal heat.

As RoHS and WEEE, ErP is part of the C $€$ marking certifying that the equipment meets the safety, health and environmental criteria and a declaration of conformity.

\subsection{Reach European Union REGulation}

REACh (Registration, Evaluation and Authorization of Chemicals) is a Regulation of the European Parliament and of the Council of the European Union, adopted on 18 December 2006 (1907/2006), which sets up a system integrated registration, evaluation and authorization system for chemical substances marketed in the European Union [9]. REACh imposes a process of registration and toxicological and environmental assessment on all products consumed in Europe without modification in each Member State. Directly or indirectly, all European companies (manufacturers, importers, distributors and / or users) are affected in varying degrees by REACh.

Registration of substances is carried out by the European Chemicals Agency (European Chemicals Agency - ECHA, Helsinki, Finland) [12]. A set of European laboratories has been selected for the assessment of health and environmental risks. As a result of these studies, ECHA examines the level of risk presented and subjects certain products to authorization, restriction or prohibition. (Some products do not fall within the scope of REACh, this is the case, for example, of radioactive substances which benefit from the specific 96/29 Euratom directive [9]).

The polymers in the REACh sense are exempted from registration because of their high average molar mass. The definition of a polymer within the meaning of the REACh regulation is as follows:

- molecules must be distributed over a range of molecular weights

- the weight percentage of any molecule of the same molecular weight shall not exceed $50 \%$

- the weight percentage of molecules containing three monomer units or above should exceed $50 \%$

(It should therefore be noted that a polymer made of two molecules is not deemed as a polymer.)

In short, REACh claims to:

- develop knowledge of the properties of substances and the risks associated with their use,

- eliminate in the long term the most dangerous substances to replace them with economic and viable substances or technologies, 
- improve communication between actors throughout the product's life cycle including chemicals,

- improve the protection of human health (workers and consumers) and the environment,

- preserve the competitiveness of European industry and its capacity to innovate,

- ensure the free movement of substances and reduce the differences of interpretation between member states.

Substances that are not registered are theoretically prohibited for commercialization in Europe: they no longer exist legally.

ECHA has identified just over 100,000 chemicals in Europe. However, only 30000 substances are marketed at more than 1 ton per year. Of these and so far, less than 3,000 have undergone detailed analyzes for their hazardous properties and the formal and quantified evaluation of toxic and environmental toxicity risks.

In Figure 1, CoRAP stands for Community Rolling Action Plan. This is in fact a list presented as a table [12]. If a substance is listed, it means that a mandated Member State has evaluated it or will do so in the next few years. The table presents the planned evaluation year and a brief description of the concern that led to its inclusion in the list, including the final assessment reports of the Member States. As of September $20^{\text {th }}, 2019$, the database contained 375 different substances, which contains substances that cannot be used (unless granted authorization) by a certain date, called Sunset Date.

RMOA (Risk Management Option Analysis) is an analysis conducted to determine the best option for managing a risk posed by a substance of potential concern. This analysis is based on the information available in the registration files submitted to ECHA. From the RMOA, two lists are made. The first file is called the restriction list or annex XVII. It gathers the restrictions adopted for a substance, a group of substances or a substance in a mixture: prohibition or limitation in the manufacture of the substance. As of September 29, 2019, it contained 73 entries.

The second file is called the Candidate list or the file of substances of very high concern (SVHC): Carcinogenic, Mutagenic, Reprotoxic (toxic for reproduction) (CMR 1A (recognized), CMR 1B (assumed) and CMR 2 (suspected) substances); Persistent, Bioaccumulative, Toxic (PBT) substances, very Persistent and very Bioaccumulative (vPvB substances); neurotoxic and eventually endocrine disruptors. As of September 29 ${ }^{\text {th }}, 2019,201$ substances are reported. It should be regularly monitored by European companies because if it does not yet prohibit market placement or even use of these substances, it triggers immediate obligations of communication of information from suppliers of preparations (paints, varnishes, glues ...) and articles $(>0.1 \%$ wt.) to the customer. An article in the sense of REACh is defined as an object to which is given during the manufacturing process a shape, a particular surface which are more important for its manufacture than its chemical composition. In other words, and to give an example, a pair of ski consisting of a board and a fastener corresponds to an article. Nevertheless, the fastener is considered as a homogenous mass therefore write their own statements is compulsory. These substances may one day be included in Annex XIV i.e. being subject to Authorization under REACh for a limiting period of time and will eventually be banned. (On September 20 ${ }^{\text {th }}, 2019$, Annex XIV contained 43 substances).

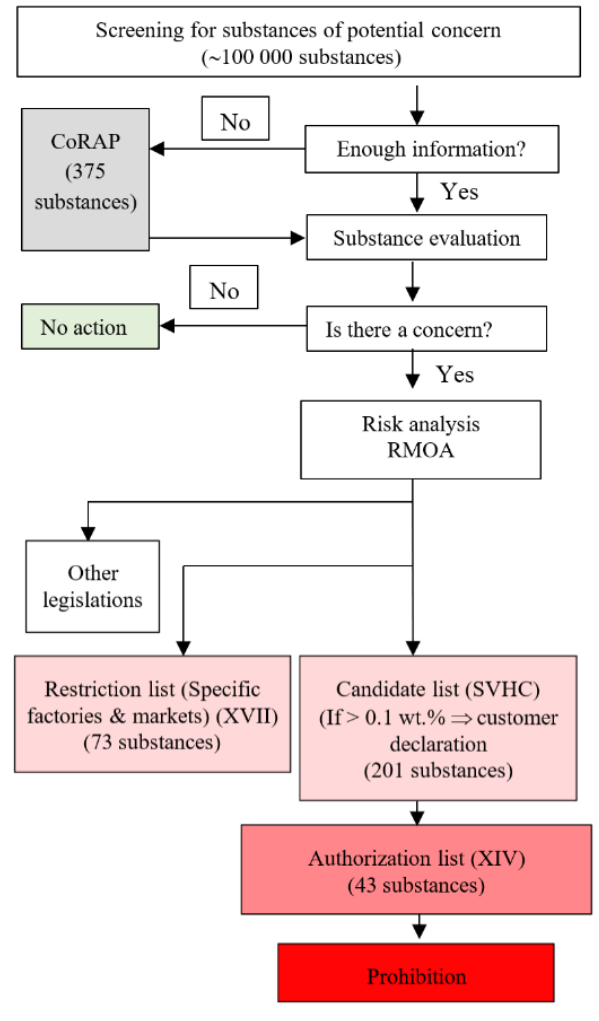

Figure 1. Schematic diagram of the chemical evaluation process

\section{STANDARDS}

The purpose of standardization is to provide reference documents containing solutions to technical and commercial problems relating to products, goods and services which arise repeatedly in relations between economic, scientific, technical or social partners [3]. The normative document refers to the fact that it is developed and adopted on the basis of consensus by the main players in a market (corporate groups or public bodies, with scientists often playing a central role). Thus, developing a standard in one area aims to define common rules to facilitate exchanges between actors. In essence, the standard is voluntary and contractual. It is not obligatory. However, its application can become so when:

- a regulatory text refers to the standard as the sole means of meeting the requirements of the text,

- the company takes a voluntary approach to differentiate itself from its competitors,

- the company must respond to a call for tenders or a simple client that requires the equipment to comply with the standard.

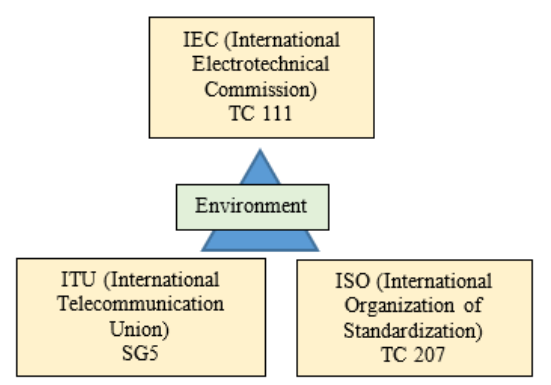

Figure 2. The three leading global standards organization in the field of the environment (TC stands for Technical Committee; SG for Study Group) 


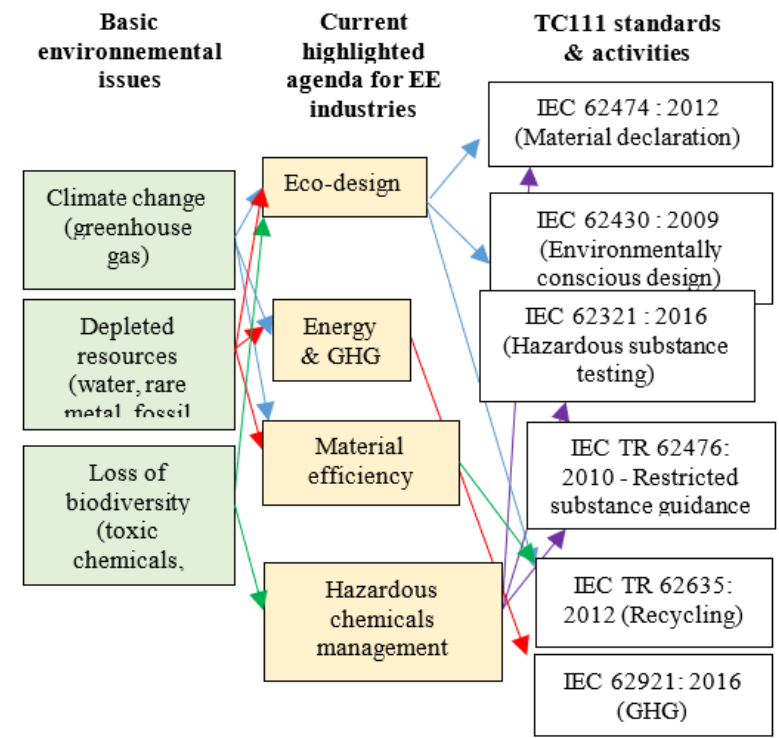

Figure 3. Relationships of Environmental Issues and IEC TC111 projects (TR stands for Technical Committee and GHG for Greenhouse Gas)

Table 2. Structure of the technical Committee 111

\begin{tabular}{|c|c|}
\hline \multicolumn{2}{|l|}{ Structure of IEC TC 111} \\
\hline WG1: Material declaration & 62474 Ed. 1.0 \\
\hline $\begin{array}{l}\text { WG2: Environmentally conscious design } \\
\text { (disbanded) }\end{array}$ & 62430 Ed. 1.0 \\
\hline WG3: Test procedures of hazardous & \\
\hline subst & $62321 \mathrm{Ed} .1 .0$ \\
\hline WG4: Green house Gasses & In progress \\
\hline $\begin{array}{l}\text { PT } 62476 \text { / Guidance for evaluation of } \\
\text { product with respect to substance use } \\
\text { restriction }\end{array}$ & 62476 Ed. 1.0 \\
\hline PT 62542: Terminology (Glossary of terms) & 62542 \\
\hline PT 62635/62650 / Recyclability & In progress \\
\hline VT 62474 / DB for material declaration & In progress \\
\hline AHG 6: Environmentally conscious design & In progress \\
\hline AHG 7: Design for Recyclability & In Progress \\
\hline $\begin{array}{l}\text { Note: WG: Working Group, i.e. a specialized group } \\
\text { is responsible for drafting a particular standard or } \\
\text { composed of experts and headed by a convener. } \\
\text { Technical Report. VT: Validation Team. DB: Da } \\
\text { Groups i.e. a group being set up within a committee } \\
\text { problem and report back to the parent committee at }\end{array}$ & $\begin{array}{l}\text { a committee that } \\
\text { deliverables. It is } \\
\text { Project Team.TR: } \\
\text { e. AHG: Ad hoc } \\
\text { into a particular }\end{array}$ \\
\hline
\end{tabular}

IEC is one of the three global organizations (IEC, ISO, ITU) which develops International Standards worldwide (Figure 2). When appropriate, IEC cooperates with ISO (International Organization for Standardization) or ITU (International Telecommunication Union) to ensure that International Standards fit together seamlessly and complement each other. These organizations have built a strategic partnership with the common goal of promoting standards specific to environmental management to help the industries manage better the impact of their activities on the environment and to demonstrate sound environmental management.

The mission of the Technical Committee 111 of IEC (IEC/TC111) is environmental standardization for electrical and electronic products and systems. It is international with more than 37 countries. TC111 has published and/or developing standardization document that support conformity assessment of products and processes, such as : standards covering test methods for the determination of critical levels of substances, guidance for evaluation of products with respect to substance-use restriction and technical documentation requirements (IEC/TR 62476: 2010 [13]), standard for technical documentation for the assess of products with respect to the restriction of hazardous substances, standards related to exchange of information on materials in products (IEC 62474 database on material declaration) [13]. The Declarable Substances List (DSL) was updated in January 2019 by addition of five of six SVHC added to the candidate list of REACh. The DSL is therefore similar to the candidate list based on the potential presence of the substances in electrical and electronic equipment (EEE).

The structure of TC 111 is reviewed every three years and updated as needed in response to new and emerging technologies, changes in regulations, and upon publication of standards. Workgroups and teams working on standardization deliverables related to environmental matters. The hereafter table 2 shows an overview of the structure of TC111 in 2019.

Figure 3 shows the different actions of TC 111 that have already been achieved or are still in progress to nudge life cycle approach.

In the context of this article, the main environmental standards IEC 62430 \& ISO 14044 have been developed.

\section{IEC 62430 (ENVIRONMENTALLY CONSCIOUS DESIGN FOR ELECTRICAL AND ELECTRONIC PRODUCTS)}

IEC 62430 is a managerial standard which is divided into two distinct parts, as displayed in Figure 4: the foundation and the elements of Environmentally Conscious Design (ECD) process [13]. This last process is consistent with a PDCA (Plan-Do-Check-Act) approach.

The IEC 62430 standard helps to establish document, apply and maintain the eco-design process as an integral part of the product design process. It is advisable to integrate this process in the management system of the company as the quality management system. The implementation of an eco-design approach in the company should not be limited to the design office but gather all other services.

Currently IEC 62430 is under revision to set up a Joint ISO/IEC standard on Environmentally Conscious Design for Electrical and Electronic Products) per approved NWIP scope as ISO/IEC 62430 Ed.2.

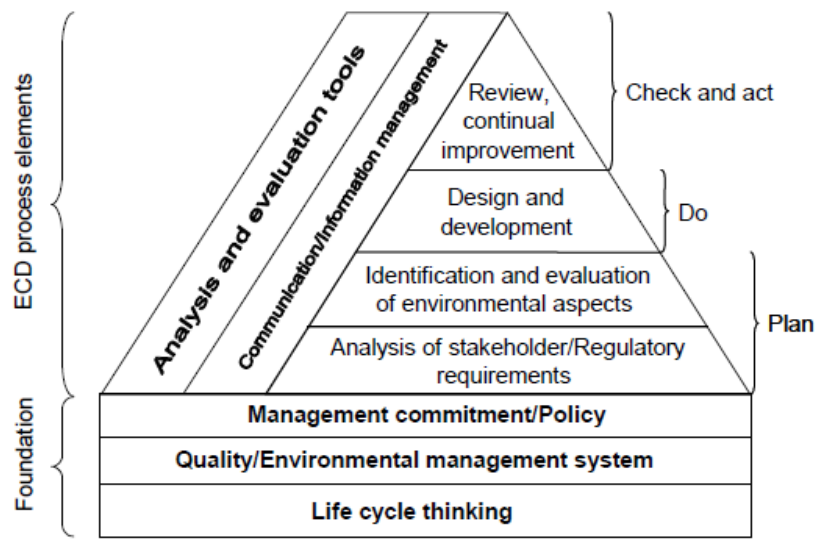

Figure 4. Overview of the Environmentally Conscious Design (ECD) process according to Annex A of IEC 62430

[13] 


\section{ISO 14044 (ENVIRONMENTAL MANAGEMENT- LIFE CYCLE ASSESSMENT-REQUIREMENTS AND GUIDELINE)}

ISO 14044 is an environmental management standard that specifies the requirements and provides guidelines for performing Life Cycle Assessments (LCA) [14]. The methodological framework for LCA was standardized between 1997 and 2000. The ISO 14044 (2006 version) standard replaces ISO 14040, ISO 14041, ISO 14042 and ISO 14043 and includes four steps (Figure 5 [3]):

- Definition of the goal and scope

o Functional unit (Quantization of the studied function)

o Delimitation of the system boundaries

o Limitations and assumptions

o Allocation methods dealing with the coproducts

- Life cycle inventory

o Collection of information

o Data calculations

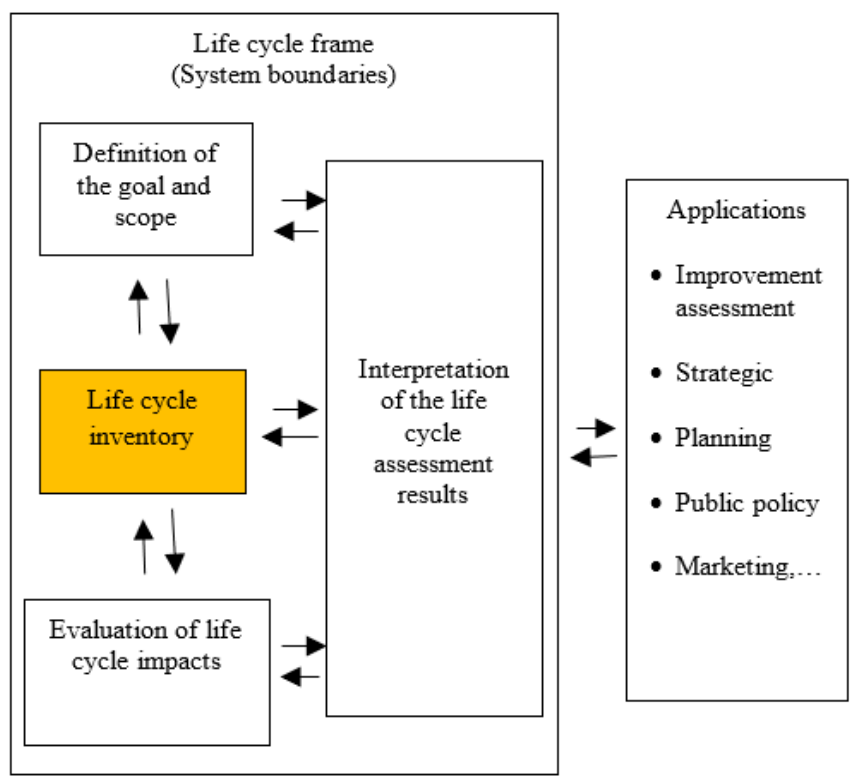

Figure 5. Life Cycle Analysis Methodology according to ISO 14044

- Evaluation of the life cycle impacts

o Choice of a characterization method

o Selections of impact categories \& category indicators

- Interpretation of LCA results

o Conclusions of the analysis (main issues)

o Evaluation of the results

o Recommendations and limitations

\subsection{Objectives and field of study (goal and scope)}

This is the first step of the study: it aims to establish for whom and why the study is conducted (Figure 5). The function of the product plays a central role. It is by defining it correctly that it becomes possible to make comparison between products and to help defining the boundaries of the system by outlining the reference flows. The objectives and scope of the study may be revised and justified due to limitations, unforeseen constraints or additional information.

\subsection{Life Cycle Inventory (LCI)}

This step consists in inventorying all the input and output flows of the system under study. The inventory and its analysis are done in several stages:

- data collection (bill of materials, processing and assembling)

- data aggregation

- data allocation (the origin of the articles and/or the materials)

The life cycle inventory is usually the most difficult phase. Indeed, the inventory is often difficult to fulfill because of the lack of an accurate knowledge on the origin of the raw materials, means of transformation, transport, etc. ...

\subsection{Evaluation of life cycle impacts}

Environmental impact assessment aims to transform an inventory of flows into a series of clearly identifiable impacts: "understanding and assessing the magnitude and significance of the potential impacts of a product system" [14]. This analysis derives directly from the upstream inventory (inputs and outputs flows). It takes place in several stages:

- selection of impact categories (e.g. Climate Change)

- selection of characterization models (for example, Global Warning Potential with assessment over a time horizon of 100 years)

- conversion of inventory results into a common unit (numeric indicator such as $\mathrm{kg}$ equivalent $\mathrm{CO}_{2}$ and aggregation within the same impact category).

Assessment of environmental impacts can be done by hand giving a very good estimation of significant issues. An Impact Score, $\mathrm{IS}_{\mathrm{c}}$, for the category c can be expressed as Eq. (1):

$$
\mathrm{IS}_{\mathrm{c}}=\sum_{\mathrm{i}}^{\mathrm{i}=\mathrm{n}} \mathrm{F}_{\mathrm{i}} \mathrm{m}_{\mathrm{i}}
$$

All elementary flows $\mathrm{m}$ (expressed in mass), classified within a specific impact category c, are multiplied by their characterization factor $F$ (the contribution per quantity of an elementary flow versus the reference substance defining the category, $\mathrm{F}_{\text {reference }}=1$ ) and summed over $\mathrm{n}$ relevant interventions $\mathrm{i}$ (emissions or resource extractions).

This work is however usually achieved with the help of a software such as EIME, Simparo with Ecoinvent database, ...

\subsection{Life cycle interpretation}

The interpretation aims to draw sound conclusions from the analysis. It is therefore necessary to analyze carefully the results and their limitations. The interpretation must emphasize the assessment methods used and must clearly establish the boundaries of the study and the process carried out. The interpretation takes place in two stages:

- Analysis of results: identify significant environmental issues and then give the meaning of the results through analytical tools

- Checking: improve or give confidence and reliability of the results of the study considering:

o Completeness check (verifies that data are available and complete)

o Sensitivity control (assesses uncertainty)

o Consistency control (checks compliance with field of study) 
In conclusion, IEC 62430 \& ISO 14044 are complementary. Indeed, one cannot go without the other: the ISO 14044 standard establishes a methodology to achieve an LCA, makes a balance of the environmental impacts of the product when it is completed, while the IEC 62430 standard carries out regular reviews taking into account all environmental obligations or stakeholders in the design and development phase of the product.

\section{FLUORATED AND GREENHOUSE GASES}

The Montreal Protocol (1997), provides a schedule for reducing production and consumption of numerous substances that are responsible for ozone depletion. Under this agreement, the industrialized countries pledge to reduce the use of HFCs by $45 \%$ by 2024 and by $85 \%$ by 2036 , compared to $2011-2013$. Ozone Depleting Substances (ODS), include 8 categories of gases: $\quad \mathrm{CFC}$ (Chlorofluorocarbons), HCFCs (Hydrochlorofluorocarbons), Halons $\left(\mathrm{CBrF}_{3}\right), \quad 1,1,1-$ Trichloroethane $\left(\mathrm{C}_{2} \mathrm{H}_{3} \mathrm{Cl}_{3}\right)$, Methyl bromide $\left(\mathrm{CH}_{3} \mathrm{Br}\right)$, methylene bromochloride $\left(\mathrm{BrClCH}_{2}\right)$. However, the list is not exhaustive. Nitrous oxide $\left(\mathrm{N}_{2} \mathrm{O}\right)$, by instance, is reported as a key compound in stratospheric ozone depletion [15].

The Kyoto Protocol requires developed countries to reduce their total greenhouse gas emissions by at least $5 \%$ between 2008 and 2012 (extended to 2020), from the 1990 level [16]. The 6 gases concerned are Carbon dioxide $\left(\mathrm{CO}_{2}\right)$, methane $\left(\mathrm{CH}_{4}\right)$, Nitrous oxide $\left(\mathrm{N}_{2} \mathrm{O}\right)$, Hydrofluorocarbons (HFC), perfluorocarbons $\left(\mathrm{C}_{\mathrm{x}} \mathrm{Fy}\right)$ and sulfur hexafluoride $\left(\mathrm{SF}_{6}\right)$.

EC 1005/2009 Regulation of 16 September 2009 [9] imposes more restrictive measures on the Member States than those of the Montreal Protocol:

- Unless exemption, the 8 gas categories are not only reduced but there are forbidden!

- Member States should define a minimum level of training for maintenance staff of equipment containing controlled substances in order to avoid and minimize leakage and emissions

- Substances contained in equipment must be recovered for processing

EC 842/2006 Regulation aimed to establish, prevent and reduce fluorinated greenhouse gas emissions covered by the Kyoto Protocol ( $\mathrm{SF}_{6}, \mathrm{HFCs}$ and PFCs). It has been repealed by EC 517/2014 Regulation (referred sometimes to as F-Gas II Regulation) [9]. It establishes a schedule for a gradual elimination of HFC up to 2030 where only specific applications without alternative will keep being authorized.

Why $\mathrm{SF}_{6}$ is used in medium and high voltage switchgears?

$\mathrm{SF}_{6}$ gas is commonly used in medium and high voltage switchgears for two functions: breaking and insulation. For breaking it offers excellent arc quenching and heat transfer properties. As an insulating medium, it has an electrical breakdown strength approximatively three times that of air at atmospheric pressure. $\mathrm{SF}_{6}$ has a number of unique properties that make it almost perfect for this application: its high dielectric strength, self-healing and non-toxic properties. Despite its many benefits and very low concentration in the atmosphere $\left(\sim 10\right.$ parts per trillion $(10 \mathrm{ng} / \mathrm{kg})$ instead of $\mathrm{CO}_{2} \sim$ 400 parts per million $(400 \mathrm{mg} / \mathrm{kg})), \mathrm{SF}_{6}$ gas has been identified as a potent greenhouse gas and is estimated to be 23,900 times more harmful than $\mathrm{CO}_{2}$ to the environment [5]. (In other words, 1 ton of $\mathrm{SF}_{6}$ is equivalent, over a 100 -year period, to 23,900 tons of emitted $\mathrm{CO}_{2}$ !). Moreover, being immune to chemical and photolytic degradation its lifetime in the atmosphere is estimated as 3200 years although $\mathrm{CO}_{2}$ is in the range 50-200 years. Electrical utilities and equipment are responsible for consuming $80 \%$ of the 10,000 tons of $\mathrm{SF}_{6}$ produced every year, an amount which is growing with the increasing global production and demand for renewable forms of energy, such as wind and solar. As a result, there has been an increase in the number of connections to the electricity grid compared with the traditional fossil power stations, with the consequential rise in the use of switchgear to deal with arcing and to stop short circuits [17].

In this context, the market trend in developing new switchgears $\mathrm{SF}_{6}$-free which might become a viable alternative and a leap forward for sustainability, health and safety. These new devices use a combination of vacuum interrupters and pure air instead of $\mathrm{SF}_{6}$ gas and allow users to take full advantage of digital features to unlock the value of data [18]. Air will be for insulation and vacuum will be for breaking. This combination enables the replacement of $\mathrm{SF}_{6}$ while maintaining the small footprint and cost-effectiveness.

\section{CONCLUSION}

Regulations and standards are essential tools for coordinating industrial efforts and stimulating the implementation of eco-design approach in companies [19]. They can play both a driving, regulator and support role. The European community has shown its willingness to be a pioneer in this field and was at the origin of numerous legislative texts relating to the improvement of product environment. The electrical and electronic sector is concerned by a large part of these texts and in particular the RoHS, WEEE, ErP directives and REACh regulation. These texts are difficult to read and often lend themselves to interpretation. However, they are interwoven in such a way that they complement each other. In addition, some countries, such as China, Japan, Canada and Australia, have similar regulations and others are under study. The generalization of such a regulatory system and the use of ISO/IEC standards should ultimately reduce the environmental impacts of electrical and electronic equipment over their entire life cycle.

EEE with optimized efficiency and more environmentally friendly will participate in the energy transition of tomorrow's electricity sector with a rise in power generation from new decarbonized intermittent renewable energy flows such as sunlight and wind.

\section{REFERENCES}

[1] INTERNATIONAL ENERGY AGENCY - World energy balances, overview. http://www.iae.com, accessed on Jan. 15, 2020.

[2] INTERNATIONAL ENERGY AGENCY - Renewables 2019. http://www.iae.com, accessed on Oct.16, 2019.

[3] Hassanzadeh, M., Metz, R. (2012). Etat de l'art législatif et normatif dans le domaine de l'écoconception des équipements électriques et électroniques européens. European Journal of Electrical Engineering, 5: 411-431. https://doi.org/10.3166/ejee.15.411-431

[4] Hassanzadeh, M., Metz, R. (2015). Eco-design of electricity distribution network equipment in ecofriendly innovations in electricity transmission and 
distribution networks. In: Bessède J.L. (eds) Eco-friendly innovations in electricity transmission and distribution networks. Woodhead Publishing Series in Energy, Amsterdam. https://doi.org/10.1016/C2013-0-16426-4

[5] Bruckner, T. (2014) Climate Change: Mitigation of Climate Change. Contribution of Working Group III to the Fifth Assessment Report of the Intergovernmental Panel on Climate Change, chapter 7: Energy Systems. https://isbnsearch.org/isbn/9781107058217

[6] IEA- Global energy \& $\mathrm{CO}_{2}$ status report 2019, http://www.iae.com, accessed on Dec.12, 2019.

[7] Barnosky, A., Hadly, E.A., Bascompte, J., Berlow, E.L., Brown, J.H., Fortelius, M., Getz, W.M., Harte, J., Hastings, A., Marquet, P.A., Martinez, N.D., Mooers, A, Roopnarine, P., Vermeij, G., Williams, J.W., Gillespie, R., Kitzes, J., Marshall, C., Matzke, N., Mindell, D.P., Revilla, E., Smith, A.B. (2012). Approaching a state shift in Earth's biosphere, Nature, 486: 52-58. https://doi.org/10.1038/nature11018

[8] SCHNEIDER ELECTRIC - https://www.schneiderelectric.com, accessed on Dec. 12, 2019.

[9] EUROPEAN UNION - http://europa.eu/index_fr.htm, accessed on Sep. 5, 2019.

[10] THE WEEE FORUM - http://weee-forum.org, accessed on Oct.16, 2019.

[11] EUROPEAN UNION - Energy, Climate change, Environment. http://ec.europa.eu/info/energy-climatechange-environment/, accessed on Oct.17, 2019.

[12] EUROPEAN UNION - http://echa.europa.eu, accessed on Oct.17, 2019.

[13] INTERNATIONAL

ECTROTECHNICAL COMMISSION - CEI 62430, Environmentally conscious design for electrical and electronic products,
Edition 1.0 and IEC TR 62476:2010, Guidance for evaluation of product with respect to substance use restriction in electrical and electronic products. https://www.iec.ch, accessed on Jan. 8, 2020.

[14] INTERNATIONAL ORGANIZATION FOR STANDARDIZATION - ISO 14044:2006, Environmental management - Life cycle assessment Requirements and guideline. https://www.iso.org/standard/38498.html, accessed on Jan. 8, 2020.

[15] Arevalo-Martinez, D.L., Kock, A., Loscher, C.R., Schmitz, R.A., Bange, H.W. (2015) Massive nitrous oxide emissions from the tropical South Pacific Ocean. Nature Geoscience, 8: 530-533. https://doi.org/10.1038/ngeo2469

[16] UNITED NATIONS - What is the Kyoto Protocol? https://unfccc.int/kyoto_protocol, accessed on Jan. 8, 2020.

[17] ADVANCDED SCIENCE NEWS - Ozin, G. SF6 worries - The most potent and persistent greenhouse gas. September 20. https://www.advancedsciencenews.com/, accessed on Jan. 9, 2020.

[18] Preve, C., Piccoz, D., Trichon, F., Maladen, R. (2019). Innovative SF6 free switch with shunt vaccum interruption technology. 25th International Conference on Electricity Distribution, Madrid, paper $n^{\circ} 770$.

[19] Hassanzadeh, M., Theoleyre, S., Jollain, C., Metz, R. (2013). Environmental Declaration in compliance with ISO 14025 thanks to a collaborative program of electrical and electronic industry: the PEP ecopassport program. Electricity Distribution. 22nd International Conference and Exhibition, Stockholm, paper $n^{\circ} 0138$. 